\title{
Chemical Vapor Deposition of Fluoroalkylsilane Monolayer Films for Adhesion Control in Microelectromechanical Systems
}

T. M. Mayer, M. P. de Boer, N. D. Shinn, P. J. Clews, T. A. Michalske

Sandia National Laboratories

Albuquerque, NM 87185

\section{Abstract}

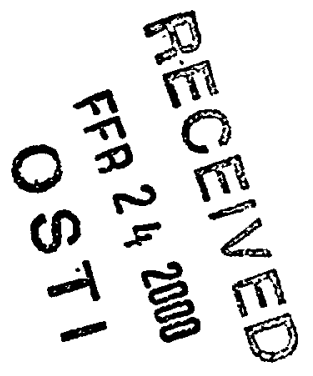

We have developed a new process for applying a hydrophobic, low adhesion energy coating to microelectromechanical (MEMS) devices. Monolayer films are synthesized from tridecafluoro-1,1,2,2- tetrahydrooctyltrichlorosilane (FOTS) and water vapor in a low-pressure chemical vapor deposition process at room temperature. Film thickness is self-limiting by virtue of the inability of precursors to stick to the fluorocarbon surface of the film once it has formed. We have measured film densities of $\sim 3$ molecules $\mathrm{nm}^{2}$ and film thickness of $\sim 1 \mathrm{~nm}$. Films are hydrophobic. with a water contact angle $>110^{\circ}$. We have also incorporated an in-situ downstream microwave plasma cleaning process, which provides a clean. reproducible oxide surface prior to film deposition. Adhesion tests on coated and uncoated MEMS test structures demonstrate superior performance of the FOT́S coatings. Cleaned, uncoated cantilever beam structures exhibit high adhesion energies in a high humidity environment. An adhesion energy of $100 \mathrm{~mJ} \mathrm{~m}^{-2}$ is observed after exposure to $>90 \%$ relative humidity. Fluoroalkylsilane coated beams exhibit negligible adhesion at low humidity and $\leq 20 \mu \mathrm{J}$ $\mathrm{m}^{-2}$ adhesion energy at $>90 \%$ relative humidity. No obvious film degradation was observed for films exposed to $>90 \%$ relative humidity at room temperature for $>24 \mathrm{hr}$. 


\section{DISCLAIMER}

This report was prepared as an account of work sponsored by an agency of the United States Government. Neither the United States Government nor any agency thereof, nor any of their employees, make any warranty, express or implied, or assumes any legal liability or responsibility for the accuracy, completeness, or usefulness of any information, apparatus, product, or process disclosed, or represents that its use would not infringe privately owned rights. Reference herein to any specific commercial product, process, or service by trade name, trademark, manufacturer, or otherwise does not necessarily constitute or imply its endorsement, recommendation, or favoring by the United States Government or any agency thereof. The views and opinions of authors expressed herein do not necessarily state or reflect those of the United States Government or any agency thereof. 


\section{DISCLAIMER}

\section{Portions of this document may be illegible in electronic image products. Images are produced from the best available original document.}




\section{Introduction}

Adhesion of moving parts is one of the more difficult problems to overcome in

fabrication of microelectromechanical systems (MEMS) ${ }^{1}$. Mechanical structures

fabricated from polycrystalline silicon inevitably oxidize to leave a high surface energy, hydrophilic surface. After etching of sacrificial oxide layers to release the mechanical parts, surface tension of aqueous etchants pulls parts together during the drying process. Upon contacting each other, hydrogen bonding between surface hydroxyl groups leads to large adhesive energies. In a high humidity ambient, this problem is exacerbated by adsorption and reaction of water with the surface and capillary condensation, effectively gluing parts together.

Various approaches have been investigated to prevent or alleviate this problem. Textured surfaces ${ }^{2}$ with small effective contact area minimize the total adhesive energy. while supercritical $\mathrm{CO}_{2}$ drying ${ }^{3}$ or sublimation dryingt processes avoid the capillary forces leading to contact during fabrication. Low surface energy, hydrophobic coatings applied to mechanical parts have been employed ${ }^{5-7}$ to discourage adhesion both during fabrication and in use, should contact occur. In this paper we address this last approach.

Hydrocarbon and fluorocarbon materials are well known for their low surface energies and hydrophobic nature. Most coating processes for MEMS devices aim to produce a thin surface layer bound to the oxidized Si and present a dense hydrocarbon or fluorocarbon surface to the environment ${ }^{1.5-7}$. The most common surface modification scheme for oxidized Si surfaces is reaction of alkylchlorosilanes with water and/or surface hydroxyl groups to form a thin alkylsilane film in a solution-based process ${ }^{\S}$. In general, the chlorosilane molecules react with water to form silanols, which then 
condense to form siloxane polymer with the elimination of water. The condensation reaction can also occur with hydroxyl groups bound to the oxide surface, yielding a Si-OSi bond, anchoring the film to the surface. The pendant alkyl groups can alsa play a role in film formation ${ }^{9,10}$. Long-chain hydrocarbon groups $\left(>\mathrm{C}_{12}\right)$ interact via van der Waals . forces to form a two-dimensionally ordered self-assembled layer, while shorter chain alkyl groups and fluorinated alkyl groups do not tend to form ordered two-dimensional structures. While these films have found widespread use in MEMS technology and elsewhere, their structure and properties are not well characterized. In particular, the extent of bonding to the surface ${ }^{11-13}$, crosslinking ${ }^{14}$, and ordering ${ }^{15-17}$ of alkylsilanes are topics of considerable discussion in the literature.

Solution-based coating processes for alkylsilane films depend on temperature ${ }^{9.18}$, availability of water ${ }^{19}$. nature of the solvent ${ }^{19}$ and concentrations of chorosilane and silanol species in solution ${ }^{20}$. Implementation of a solution-based coating process into MEMS technology has been problematic due to a lack of understanding of this process, and apparently narrow process windows.

Vapor phase coating processes using volatile fluorinated alkylsilanes have also been reported ${ }^{21-23}$. Vapor phase processes offer a number of distinct advantages compared to solution-based processes. One can avoid problems associated with solutionbased coating, including incomplete wetting of high aspect ratio structures, diffusion limited transport of reagents into confined areas. control of minute quantities of dissolved water in nonaqueous solvents, uncertain reaction kinetics of chlorosilanes in solution, micelle formation, and disposal of organic solvent waste. Vapor phase processes provide efficient transport into high-aspect ratio structures, good control of reagent supply. have 
no solvent waste, and allow convenient, in-situ cleaning and preparation of surfaces immediately prior to deposition.

We have developed a low pressure, vapor-phase method for coating MEMS devices with a hydrophobic fluorocarbon film, which realizes many of the advantages listed above. In this process we use a volatile fluoroalkylsilane as precursor for a chemical vapor deposition (CVD) process. In a vacuum chamber, controlled amounts of silane precursor and water vapor react on the surface of the sample to form silanols, with a fluoroalkyl side chain to provide a hydrophobic. low energy surface. This CVD process does require that mechanical parts be released and dried prior to introduction to the deposition chamber, so that sacrificial oxide etching must be followed by a supercritical $\mathrm{CO}_{2}$ or sublimation drying procedure to produced free, released parts.

In this paper we outline the coating process and reactor. details of an in-situ plasma cleaning process we have incorporated, in-situ ellipsometric and quartz crystal microbalance measurements of the film deposition. characterization of the film by contact angle measurements and atomic force microscopy. and adhesion measurements using a cantilever beam test structure. Monolayer films grown by this method are shown to be dense, continuous, possess low adhesion energies. and are robust toward degradation in high humidity environments.

\section{Experimental}

The chemical vapor deposition apparatus is shown schematically in Figure 1. It is a simple vacuum system, pumped by a tubomolecular pump and a mechanical roughing pump. The fluoroalkylsilane and water precursors enter the reactor though high precision leak valves from separate reservoirs. An Evenson-type microwave cavity surrounds a 
quartz flow tube, which can be used to excite a gas for cleaning substrates prior to the film coating. Cleaning is accomplished using a discharge in $0.1-0.5$ torr $\mathrm{O}_{2}$ or $\mathrm{H}_{2} \mathrm{O}$ vapor, at $20-30 \mathrm{~W}$ forward power using $2.54 \mathrm{GHz}$ excitation. The wafer susceptor contains a resistive heater, which allows heating to $>400^{\circ} \mathrm{C}$. Strain-free quartz windows oriented at $70^{\circ}$ from the surface normal are also incorporated for in-situ ellipsometric measurements of the sample during processing.

The fluoroalkylsilane precursor used in this study is tridecafluoro-1.1.2,2tetrahydrooctyltrichlorosilane $\left(\mathrm{CF}_{3}\left(\mathrm{CF}_{2}\right)_{5}\left(\mathrm{CH}_{2}\right)_{2} \mathrm{SiCl}_{3}\right)$, which we label FOTS. This compound has a vapor pressure of approx. 0.3 torr at room temperature, and is thus convenient for use as a CVD precursor. We have also used the 10 -carbon chain analogue (FDTS), however it has significantly lower vapor pressure, which leads to considerably longer process time. The silane precursor is vacuum distilled prior to use. Deionized and ultra filtered water with resistivity $>18 \mathrm{M} \Omega$ is used. The water is degassed on the vacuum system prior to use. Both precursor reservoirs are maintained at room temperature.

We employ spectroscopic ellipsometry (SE) as well as quartz crystal microbalance (QCM) techniques for in-situ observations of film growth. Ellipsometry provides two measurable quantities: $\Delta$ (the phase difference between the two different polarization components - the $\mathrm{p}$ and $\mathrm{s}$ waves), and $\tan \Psi$ (the ratio of the magnitudes of the reflection coefficients of the $\mathrm{p}$ and s waves) of the reflected light beam. For in-situ growth studies, we will display real-time measurements of $\Delta$, which is the more sensitive and changes linearly with film thickness in this regime. Ellipsometric measurements of 
nanometer thick films are very precise, having the ability to detect changes in film thickness on the order of $0.01 \mathrm{~nm}$. However, determination of absolute film thickness in this regime is problematic. For very thin films one must either know or assume a value for the film's index of refraction in order to determine the thickness. For this reason we also employ a quartz crystal microbalance (QCM) to obtain an independent measure of the areal density of the film. Ex-situ measurements include ellipsometry and $\mathrm{x}$-ray. photoelectron spectroscopy (XPS) for film thickness and surface composition. Water contact angles are measured by the sessile drop technique. AFM measurements are made in contact mode using $\mathrm{Si}_{3} \mathrm{~N}_{4}$ cantilever tips, with the minimum applied load consistent with stable imaging.

We measure adhesion using the cantilever beam adhesion test device and procedure described previously 24,25 . The test device is mounted in an environmental chamber on an interference microscope stage. Long $(1000-2000 \mu \mathrm{m})$ cantilever beams of polycrystalline Si are brought into contact with a polycrystalline Si landing pad by electrostatic actuation. The beam and landing pad are both connected to ground so that no potential difference exists between them. An actuation voltage is applied to a small pad located near the support post of the beams to bring the beam into contact with the landing pad. After the actuation voltage is removed, the restoring force of the beam acts to pull the beam away from the landing pad. This is opposed by the adhesive force of the interface of the beam with the landing pad. The result is that beams are adhered over a length such that the adhesion energy and strain energy in the beam are in equilibrium. We measure the beam deflection using the fringe pattern in the interference microscope. Through a fracture mechanics analysis, the adhesive energy of the contact can be 
determined quantitatively by measuring the 'crack length' of the adhered beam 24,26 . The adhesive energy, $\Gamma$, in $\mathrm{J} \mathrm{m}^{-2}$, is given by

$$
\Gamma=\frac{3}{2} E \frac{h^{2} t^{3}}{s^{4}},
$$

where $E$ is Young's modulus of the polycrystalline Si beam, $h$ is the height of the beam above the landing pad, $t$ is its thickness, and $s$ is the crack length - the length from the support post to the point at which the beam adheres to the landing pad. In this study, we measure adhesion of uncoated beams and beams coated with FOTS as a function of relative humidity in a flowing gas of $\mathrm{N}_{2} \div \mathrm{H}_{2} \mathrm{O}$ vapor.

Samples used are: a) Flat, single crystal Si samples, which have undergone standard processing steps used in fabrication of MEMS devices, including release etch in $\mathrm{HF}$, reoxidation in $\mathrm{H}_{2} \mathrm{O}_{2}$, transfer to methanol, and supercritical $\mathrm{CO}_{2}$ drying. These samples are used for in-situ and ex-situ ellipsometric measurements, contact angle

measurements, XPS, and AFM measurements of FOTS film deposition and properties. b) Polycrystalline Si films deposited onto $\mathrm{Cr}$ metal electrodes on quartz wafers for QCM measurements. c) Polycrystalline Si cantilever beam adhesion test structures fabricated by the same process used in (a), for adhesion test measurements.

\section{Results and Discussion}

\section{A. Surface Cleaning}

Samples often exhibit significant surface contamination after supercritical $\mathrm{CO}_{2}$ drying, resulting in inconsistent and nonuniform coating and adhesion behavior ${ }^{27}$. Since 
we cannot introduce parts into an aqueous cleaning environment after the release etch we have developed an in-situ plasma cleaning process which can be easily integrated with the coating process. After loading into the vacuum chamber and prior to coating, we expose the sample to a downstream microwave discharge in flowing $\mathrm{O}_{2}$ or $\mathrm{H}_{2} \mathrm{O}$ vapor at approx. $0.1-0.3$ torr, at $20-30 \mathrm{~W}$ forward power. The water contact angle measured before and after cleaning serves as a gauge of the effectiveness of the cleaning process. Figure 2 shows that parts are initially somewhat hydrophobic, with contact angle of $60-$ $70^{\circ}$. Separate XPS measurements confirm that parts typically have a high level of carboncontaining contamination. Cleaning in $\mathrm{H}_{2} \mathrm{O}$ vapor discharge for $>10$ min. results in a surface with a contact angle of $<5^{\circ}$ (Figure 2) with no measurable carbon contamination. We obtain similar results for cleaning in $\mathrm{O}_{2}$ discharges. Although these results are for flat surfaces with line-of-sight exposure to the discharge flux. molecular flow conditions ensure that the underside of cantilever structures and confined areas of high aspect ratio structures also receive sufficient reactive flux to remove organic contaminants. Test measurements on cantilever beam structures confirm this. This cleaning process then provides us with a reproducible, hydrophilic surface on which to deposit the fluoroalkylsilane film. We should also note that the $\mathrm{O}_{2}$ or $\mathrm{H}_{2} \mathrm{O}$ discharge is also quite effective at removing fluorocarbon films deposited by the process described below.

\section{B. Film Deposition}

The film coating process begins by closing the pumping valve and introducing FOTS to a static gas pressure of. $0.1-0.15$ torr. (This takes about 10 minutes in this experiment because of the low vapor pressure of the FOTS, and small conductance of the leak valve used.) Upon reaching the desired pressure, we close the FOTS leak valve, and 
open the $\mathrm{H}_{2} \mathrm{O}$ leak valve. Water vapor is admitted to a total pressure in the chamber of $0.3-0.8$ torr, at which point the $\mathrm{H}_{2} \mathrm{O}$ valve is closed. The gases are then left to react with the wafer surface under static conditions for varying lengths of time. Growth of the film during this time is monitored by in-situ ellipsometry, shown in Figures 3-4. (Thickness estimates in Figures 3-4 are based on an assumed index of refraction of the FOTS films of 1.498 at the observation wavelength of $350 \mathrm{~nm}$.)

Initial adsorption of FOTS to the surface is confirmed by a small decrease in $\Delta$, however coverage is low, corresponding to an equivalent film thickness of $0.3-0.4 \mathrm{~nm}$. Moreover, this layer is not tightly bound to the surface. and will desorb upon pumping away the FOTS precursor, as shown in Figure 3. It is often assumed that chlorosilanes will react with surface hydroxyl groups to form covalent linkages to the surface. However, Klaus and coworkers 28 have found that surface hydroxyl groups react with gaseous chlorosilanes only at high temperature and very high doses of the chlorosilane. Substantial desorption of the FOTS precursor suggests that rapid reaction with surface hydroxyl groups does not occur at room temperature. A stable film is formed only after introduction of water vapor, shown in Figure 4. The reaction reaches a limiting film thickness of approx. $1 \mathrm{~nm}$ after approx. 15 minutes exposure to the mixed precursors. Repeated cycles of FOTS and $\mathrm{H}_{2} \mathrm{O}$ exposure result in only minor additional film growth. A fully dense FOTS film with extended alkyl chains should have a thickness of approx. $1.2 \mathrm{~nm}$, so it appears that the limiting thickness of FOTS film formed in this process corresponds to a reasonably well packed monolayer film. We believe the self-limiting behavior is caused by the inability of the precursor molecules to stick to the-fluoroalkylterminated surface, limiting film growth to one molecular layer. 
An independent, quantitative measure of areal density of deposited material is available from QCM measurements. Figure 5 shows the change in QCM frequency observed during a similar deposition cycle of FOTS and FOTS $+\mathrm{H}_{2} \mathrm{O}$ at room temperature. (Both QCM and SE measurements could not be made on the same sample because of the surface roughness of the polycrystalline Si film on the QCM sample.) The sensitivity of the QCM is $17.7 \mathrm{ng} \mathrm{cm}^{-2} \mathrm{~Hz}^{-1}$. Assuming the FOTS reacts on the surface to replace $\mathrm{Cl}$ atoms with $\mathrm{OH}$, this measurement gives an upper limit for the surface density of $2.8 \times 10^{14}$ molecules $\mathrm{cm}^{-2}$ after a single cycle of FOTS $+\mathrm{H}_{2} \mathrm{O}$ exposure. Considering the van der Waals radius of the fluorocarbon pendant group 29.30 , the maximum packing density is $3-4 \times 10^{14} \mathrm{~cm}^{-2}$. The QCM measurement then indicates that the film is quite well packed, and the measured surface density is consistent with the estimated film thickness determined from the ellipsometric measurements.

Of course these measurements give us no indication of ordering or structure of the film, or the extent of condensation to form siloxane linkages in the film. We note that Hoffman et al 22 observed an increase in tilt angle of the fluoroalkyl chain with respect to the surface with increasing packing density for a mono-functional fluoroalkylsilane deposited from the gas phase. Stevens ${ }^{14}$ has also noted that ordered alkylsilane films are sterically hindered from forming siloxane crosslinks between one another. From our measurement of high packing density in these films combined with these previous observations, we expect that our films consist primarily of silanol molecules. not chemically bound to the surface nor crosslinked to each other, with the fluoroalkyl chains pointing out from the surface. 
Film thickness and water contact angle as a function of FOTS $+\mathrm{H}_{2} \mathrm{O}$ reaction time and deposition temperature are shown in Figures 6,7. All films are hydrophobic, with contact angle $>100^{\circ}$. For a given reaction time, thickness and contact angle decrease with increasing temperature. We ascribe this to a decreased sticking probability of the precursors with the surface at elevated temperature.

AFM images, shown in Figure 8, reveal a smooth, featureless surface, with no indication of partial coverage or three-dimensional features in the film. RMS roughness of the surface in Figure10 is $0.23 \mathrm{~nm}$ - equivalent to the roughness of the starting substrate. Simultaneous lateral force images also reveal no significant inhomogeneity in film properties.

\section{Adhesive Properties}

Adhesive properties of surfaces coated by these films have been measured using the cantilever beam adhesion test structure described earlier. Adhesion of coated and cleaned, but uncoated, beams was measured at ambient humidity levels of $5 \%-95 \%$ relative humidity $(\mathrm{RH})$ at room temperature. For this test an array of beams between 1000 and $2000 \mu \mathrm{m}$ in length were brought into contact to a crack length of approx. $500 \mu \mathrm{m}$ by application of $100 \mathrm{~V}$ bias to the actuation electrode. Upon removing the actuation bias, we measure the crack length for the adhered beams to extract the adhesion energy according to equation 1 . This procedure was repeated at increasing humidity levels over a period of three days.

Uncoated beams cleaned in $\mathrm{O}_{2}$ plasma $(0.15$ torr, $30 \mathrm{~W}, 30 \mathrm{~min}$.) were tested both to measure the adhesion of bare oxide surfaces as well as to examine the efficacy of the 
plasma cleaning process. At low humidity, plasma cleaned beams did not adhere upon initial actuation. As the humidity increases above $70 \% \mathrm{RH}$ beams start to adhere and the crack length decreases with time at high humidity levels. Adsorption of water to the oxide surface increases the adhesion energy, and capillary condensation at the crack tip draw the beams together 25,27 . Finally at $>90 \% \mathrm{RH}$, all beams are adhered over nearly their entire length, shown in Figure 9. From equation 1 we calculate the adhesion energy to be $\sim 100 \mathrm{~mJ} / \mathrm{m}^{2}$. Adsorption of water and large adhesion energy indicates that the oxidized surfaces of the beam are indeed hydrophilic, and that the plasma cleaning process is effective even on surfaces not in line-of-sight to the flux of reactive species from the plasma. Adhesion tests on parts that have not received the in-situ plasma clean have yielded inconsistent and non-uniform results indicative of a high degree of surface contamination. More details of the performance of the cleaning process and adhesion of cleaned, oxidized beams will be presented in a separate publication.

FOTS coated parts were tested in the same manner. Initial actuation resulted in no adhered beams, shown in Figure 10a. Exposure to increasing humidity and repeated actuation also caused no measurable adhesion up to $90 \% \mathrm{RH}$. The minimum adhesion energy we can measure based on equation 1 and the beam dimensions is $\sim 1 \mu \mathrm{J} \mathrm{m}^{-2}$. At 95\% RH exposure for $17 \mathrm{hr}$., only a few beams adhered at crack lengths of $800-1000 \mu \mathrm{m}$, shown in Figure 10b. Adhesive energy of these beams is $10-20 \mu \mathrm{J} \mathrm{m}^{-2}$, or roughly three orders of magnitude less than that of clean, uncoated beams. Most beams in Figure 10b remain free or stuck only at their tips. indicating an even smaller adhesive energy. 
Performance of the FOTS coatings is comparable to or superior to FDTS or ODTS coatings applied in a liquid environment in a number of ways. Adhesion energy of beams at low humidity is equal to or better than solution-coated parts. In this work we observe no adhered beams at low humidity, resulting in an upper limit to the adhesion energy of $\sim 1 \mu \mathrm{J} \mathrm{m}^{-2}$. Adhesion energies of $10-20 \mu \mathrm{J} \mathrm{m}^{-2}$ have been measured for both solution-coated ${ }^{25}$ and CVD deposited films on other samples, however. (Adhesion behavior at low humidity may be dominated by aspects of surface roughness and coating uniformity, which are not fully characterized from run to run.) At high humidity, adhesion of solution-coated parts shows evidence of degradation of the coating due to water uptake, and increased adhesion as the film degrades ${ }^{25}$.

Film degradation at high humidity is thought to be due to defects in the film. exposing small areas of hydrophilic substrate, allowing water adsorption and condensation ${ }^{25}$. We see no evidence for this type of degradation in the CVD deposited films. An AFM image of a FOTS coated sample exposed to $>90 \% \mathrm{RH}$ for $>2+\mathrm{hr}$. is shown in Figure 11. There is no evidence for gross degradation of the film. comparable to that observed for solution coated parts, although there may be an increase in small particulates on the exposed sample shown in Figure 11. We' are not yet certain whether these particulates are evidence for the beginning of film degradation, or the result of handling the sample outside of a clean room environment. The contact angle remains high on this surface ( $117^{\circ}$ measured after exposure. vs. $114^{\circ}$ measured before).

Other modes of film degradation have not been investigated in detail. Sung et al ${ }^{31}$ and Kluth et al ${ }^{32,33}$ have reported that ODTS films thermally decompose in racuum above $350^{\circ} \mathrm{C}$, while FDTS films have shown better performance after packaging 
operations that involve heating to $400^{\circ} \mathrm{C}$ in an inert atmosphere ${ }^{34}$. We have made preliminary studies that suggest that CVD deposited FOTS films are robust at temperatures up to $450^{\circ} \mathrm{C}$ in vacuum. No obvious film breakdown was obseryed in AFM images, and the contact angle remains $>100^{\circ}$. We have as yet no information on film degradation in atmosphere or oxidizing environments. Nor have we investigated the effects of friction and wear of these films in micromachine applications. Future studies will address these issues in more detail.

\section{Summary}

We have developed a new process for applying a hydrophobic, low adhesion energy coating to MEMS devices. A fluorinated alkylsilane monolayer film is synthesized in a low-pressure chemical vapor deposition process using tridecafluoro1,1,2,2- tetrahydrooctyltrichlorosilane (FOTS) and water vapor precursors at room temperature. Film thickness is self-limiting by virtue of the inability of precursors to stick to the fluorocarbon surface of the film once it has formed. We have measured film densities of $\sim 3$ molecules $\mathrm{nm}^{2}$ and film thickness of $\sim 1 \mathrm{~nm}$. Films are hydrophobic, with a water contact angle $>110^{\circ}$.

We have also demonstrated an in-situ downstream microwave plasma cleaning process using $\mathrm{O}_{2}$ or $\mathrm{H}_{2} \mathrm{O}$. Parts initially contaminated with hydrocarbons are effectively cleaned, leaving a uniform hydrophilic oxide surface on which to grow the fluorocarbon * coating.

Adhesion tests on coated and uncoated MEMS test structures demonstrate superior performance of the FOTS coatings. Cleaned. uncoated cantilever beam 
structures exhibit high adhesion energies in a high humidity environment. Adhesion energy of $100 \mathrm{~mJ} \mathrm{~m}^{-2}$ is observed after exposure to $>90 \%$ relative humidity. FOTS coated beams exhibit negligible adhesion at low humidity and $\leq 20 \mu \mathrm{J} \mathrm{m}^{-2}$ adhesion.energy at 95\% RH. No marked film degradation was observed for films exposed to $95 \% \mathrm{RH}$ at room temperature for $17 \mathrm{hr}$.

\section{Acknowledgements}

We wish to thank S. M. George, B. C. Bunker, R. W. Carpick, M. J. Stevens, and M. T. Dugger for helpful discussions, and D. C. Jones for technical assistance. Sandia is a multiprogram laboratory operated by Sandia Corp., a Lockheed-Martin Company, for the U.S. Department of Energy under contract no. DE-AC04-94Al85000. 


\section{References}

1 R. Maboudian, Surface Science Reports 30, 209-270 (1998).

2 R. L. Alley, P. Mai, K. Komvopoulos, and R. T. Howe, , Yokohama. 1993, p. 288-292.

3 G. T. Mulhern, D. S. Soane, and R. T. Howe, , Yokohama, 1993, p. 296-300.

4 H. Guckel, J. J. Sniegowski, t. R. Christenson, and F. Raissi, Sensors and Actuators A 21-23, 346 (1990).

5 R. L. Alley, G. J. Cuan, R. T. Howe, and K. Komvopoulos, , Hilton Head, SC, 1992, p. 202-207.

6 M. R. Houston, R. Maboudian, and R. T. Howe, . Hilton Head. SC. 1996. p. 4247.

7 M. Mehregany, S. D. Senturia, and J. H. Lang, Ieee Transactions On Electron Devices 39, 1136-1143 (1992).

8 E. P. Pleudeman, Silane Coupling Agents (Plenum, New York, 1990).

9 A. N. Parikh, D. L. allara, I. Ben Asouz, and F. Rondelez, Journal of Physical Chemistry 98, 7577-7590 (1994).

10 A. Ulman, An introduction to ultrathin organic films: from Langmuir-Blodgett to self-assembly (Academic Press, Boston. 1991).

11 C. P. Tripp and M. L. Hair, Langmuir 8, 1961-1967 (1992).

12 C. P. Tripp and M. L. Hair, Langmuir 11. $1215-1219$ (1995).

13 C. P. Tripp and M. L. Hair, Langmuir 11, 149-155 (1995).

14 M. J. Stevens, Langmuir 15, 2773-2778 (1999).

15 D. L. Allara, A. N. Parikh, and F. Rondelez, Langmuir 11, 2357-2360 (1995).

16 M. W. Tsao, C. L. Hoffmann, J. F. Rabolt. H. E. Johnson, D. G. Castner. C. Erdelen, and H. Ringsdorf, Langmuir 13, 4317-4322 (1997).

17 R. Banga, J. Yarwood, and A. M. Morgan. Langmuir 11, 618-622 (1995).

18 R. R. Rye, Langmuir 13, $2588-2590$ (1997).

19 M. E. McGovern, K. M. R. Kallury, and .M. Thompson. Langmuir 10, 3607-3614 (1994).

20 B. C. Bunker, R. W. Carpick, M. Hankins. M. L. Thomas, R. Assink. M. P. d. Boer, J. M. Martin, and G. Gulley, Langmuir submitted (1999).

21 A. Hozumi, K. Ushiyama, H. Sugimura, and O. Takai, Langmuir (1999).

22 P. W. Hoffmann, M. Stelzle, and J. F. Rabolt, Langmuir 13, 1877-1880 (1997).

23 H. Tada and H. Nagayama, Langmuir 10, 1472-1476 (1994).

24 M. P. deBoer and T. A. Michalske, Journal of Applied Physics 86, 817-827 (1999). 
25 M. P. deBoer, T. M. Mayer, R. W. Carpick, T. A. Michalske, U. Srinivasan, and R. Maboudian, Langmuir submitted (1999).

26 H. L. Ewalds and R. J. H. Wanhill, Fracture Mechanics (Edward Arnold and Delftse Uitgevers Maatschapij, London, 1991).

27 M. P. deBoer, P. J. Clews, B. K. Smith, and T. A. Michalske, Mat. Rès. Soc. Proc. 518, 131-136 (1998).

28 J. W. Klaus, A. W. Ott, J. M. Johnson, and S. M. George, Applied Physics Letters 70, 1092-1094 (1997).

29 H. Tadokoro, Structure of Crystalline Polymers (Wiley-Interscience. New York, 1979).

30 S. T. Cui, J. I. Siepmann, H. D. Cochran, and P. T. Cummings, Fluid Phase Equilibria 146, 51-61 (1998).

31 M. M. Sung, G. J. Kluth, O. W. Yauw, and R. Maboudian, Langmuir 13, 61646168 (1997).

32 G. J. Kluth, M. M. Sung, and R. Maboudian, Langmuir 13, 3775-3780 (1997).

33 G. J. Kluth, M. Sander, M. M. Sung, and R. Maboudian, Journal of Vacuum Science \& Technology a-Vacuum Surfaces and Films 16, 932-936 (1998).

34 U. Srinivasan, M. R. Houston, R. T. Howe, and R. Maboudian. Journal of Microelectromechanical Systems 7, 252-260 (1998). 


\section{Figures}

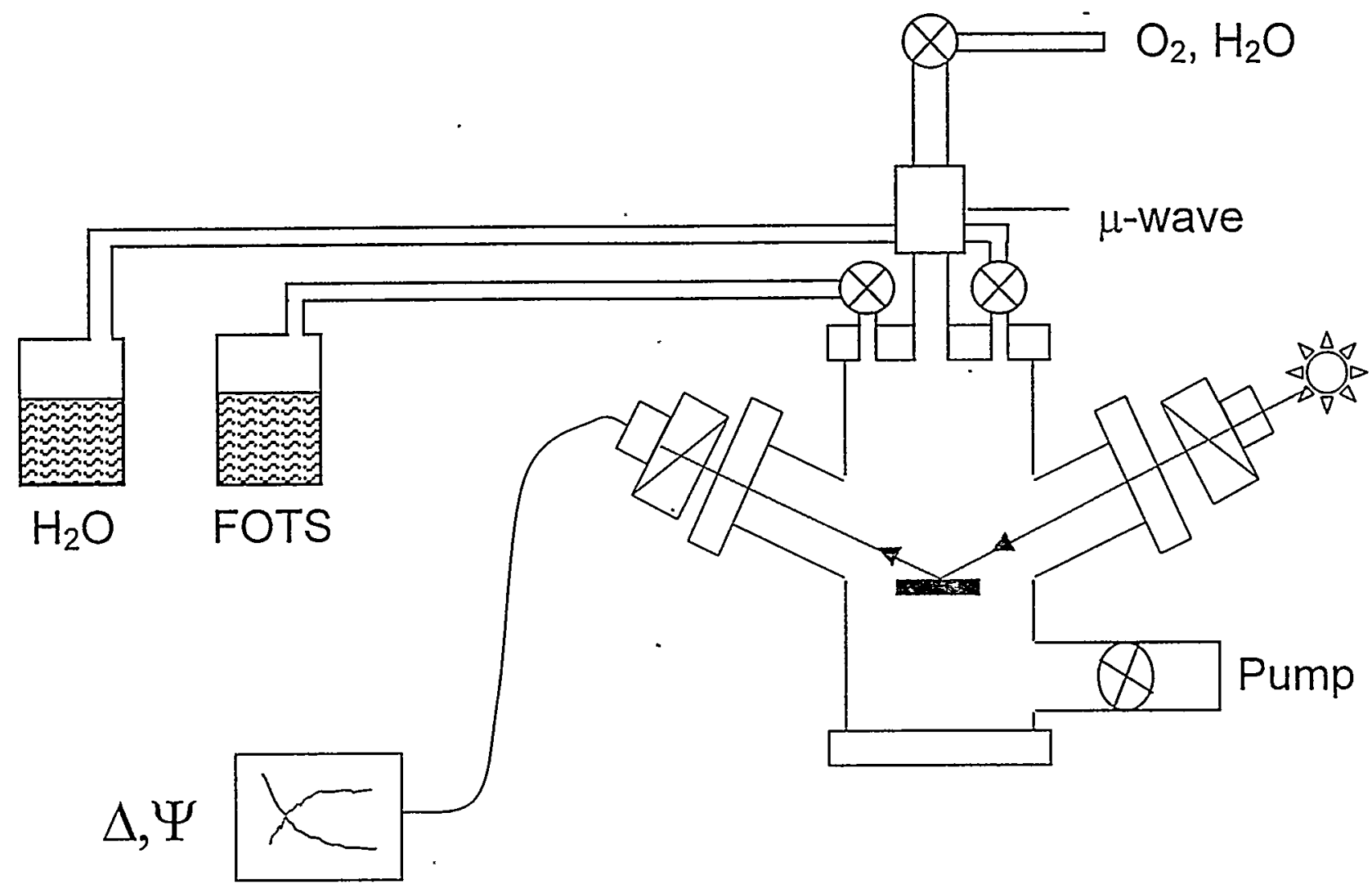

Figure 1. Schematic of the apparatus used for chemical vapor deposition of fluoroalkylsilane films. FOTS and $\mathrm{H}_{2} \mathrm{O}$ precursors are introduced through high precision variable leak valves. Pumping speed is controlled with a throttle valve. An Evenson cavity surrounds a quartz tube for microwave downstream plasma cleaning. Strain-free quartz windows at $70^{\circ}$ from the sample normal allow access for an in-situ spectroscopic ellipsometer. The sample stage includes height and tilt adjustments for the ellipsometer, and a resistive heater. 


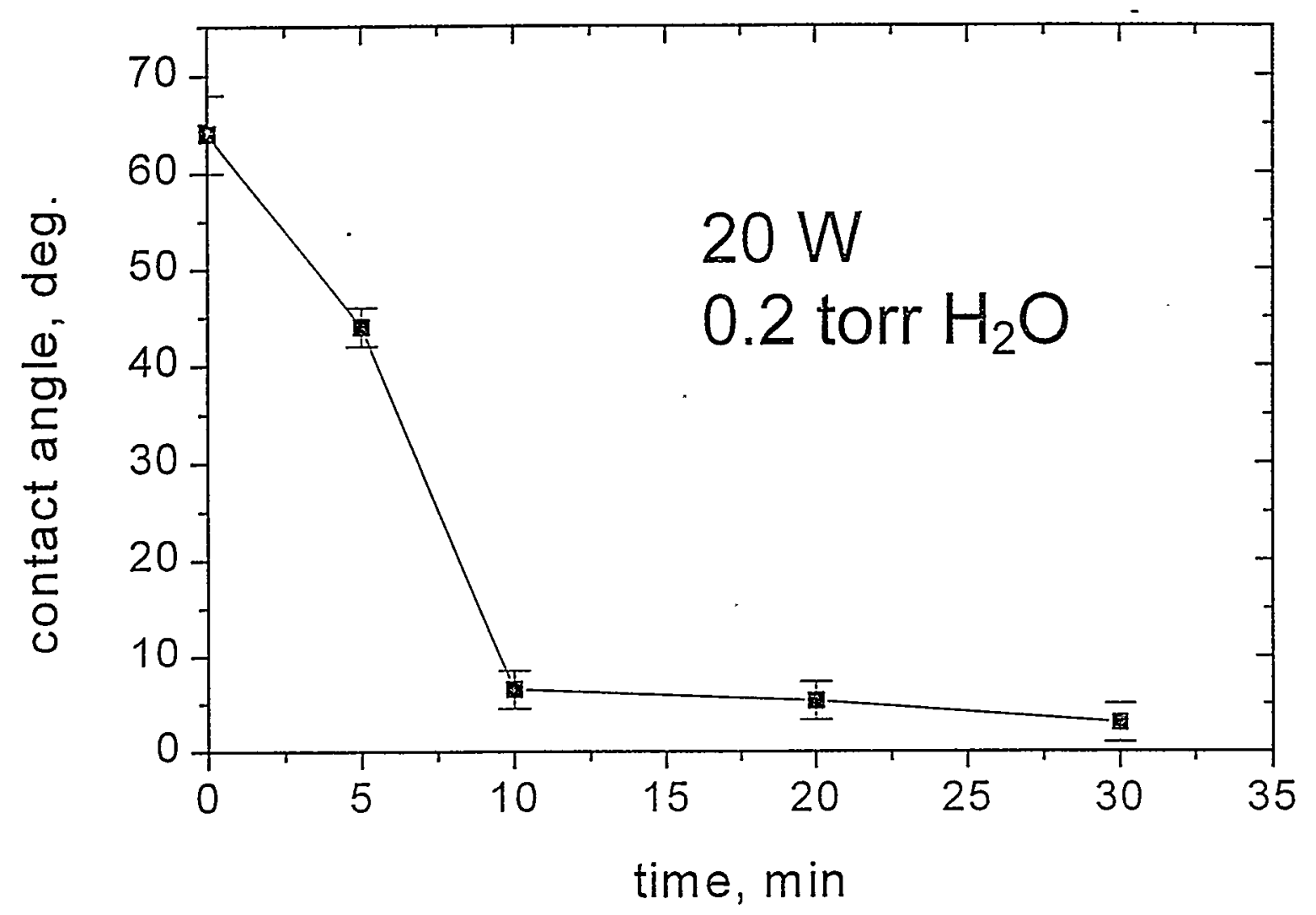

Figure 2. Water contact angles measured on supercritical $\mathrm{CO}_{2}$ dried, oxidized $\mathrm{Si}$ samples, as a function of exposure time in a downstream microwave plasma in $\mathrm{H}_{2} \mathrm{O}$ vapor at room temperature. 


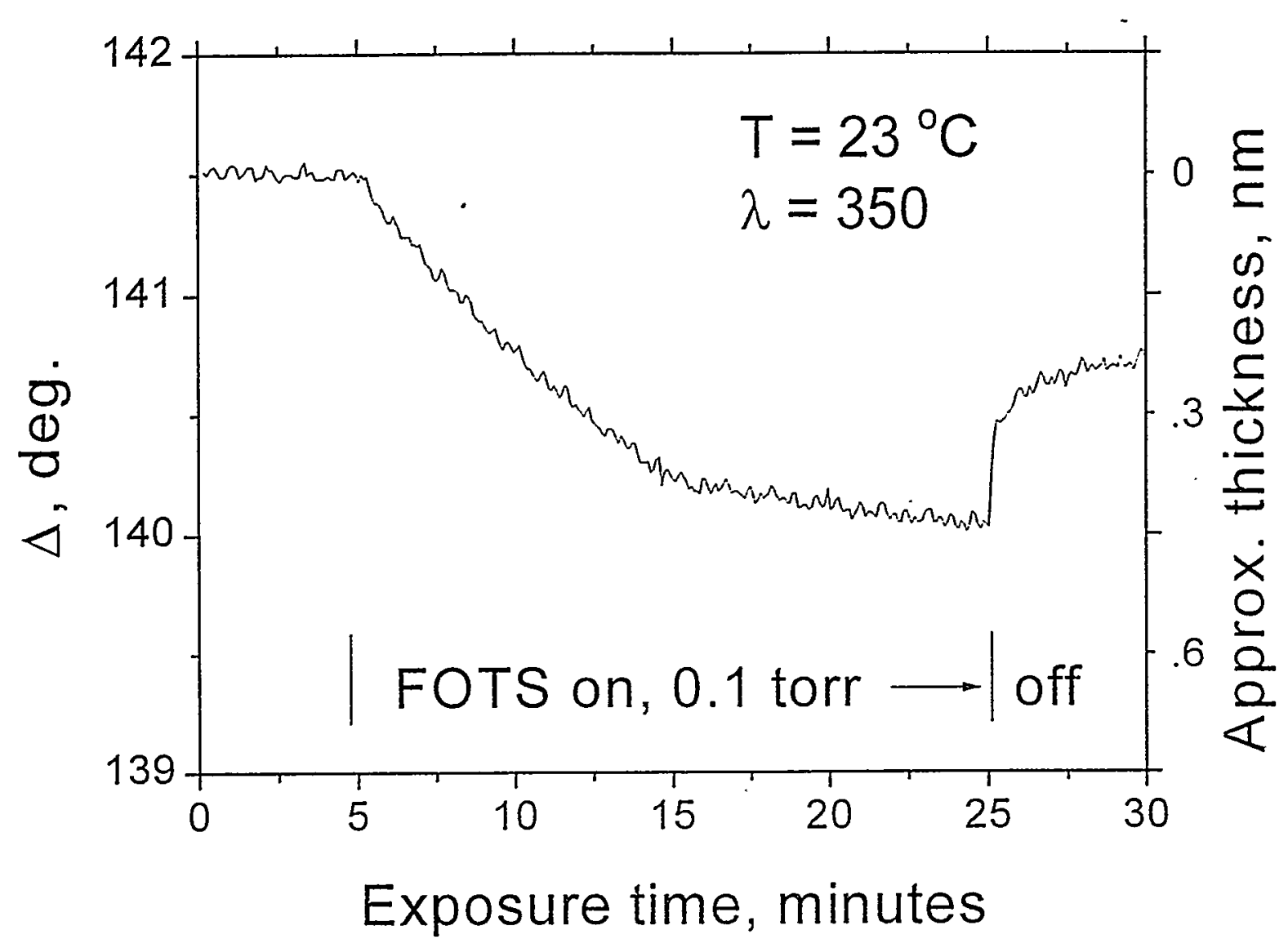

Figure 3. In-situ ellipsometric measure of adsorption of FOTS precursor to clean oxidized Si surface at room temperature. Pressure increases to 0.1 torr over about a 10minute period, at which time the FOTS valve is closed, and the pressure remains static for an additional 10 minutes. After twenty minutes, the vacuum valve is opened, and a substantial quantity of the adsorbed precursor desorbs from the surface. Measurements are made at wavelength of $350 \mathrm{~nm}$. 


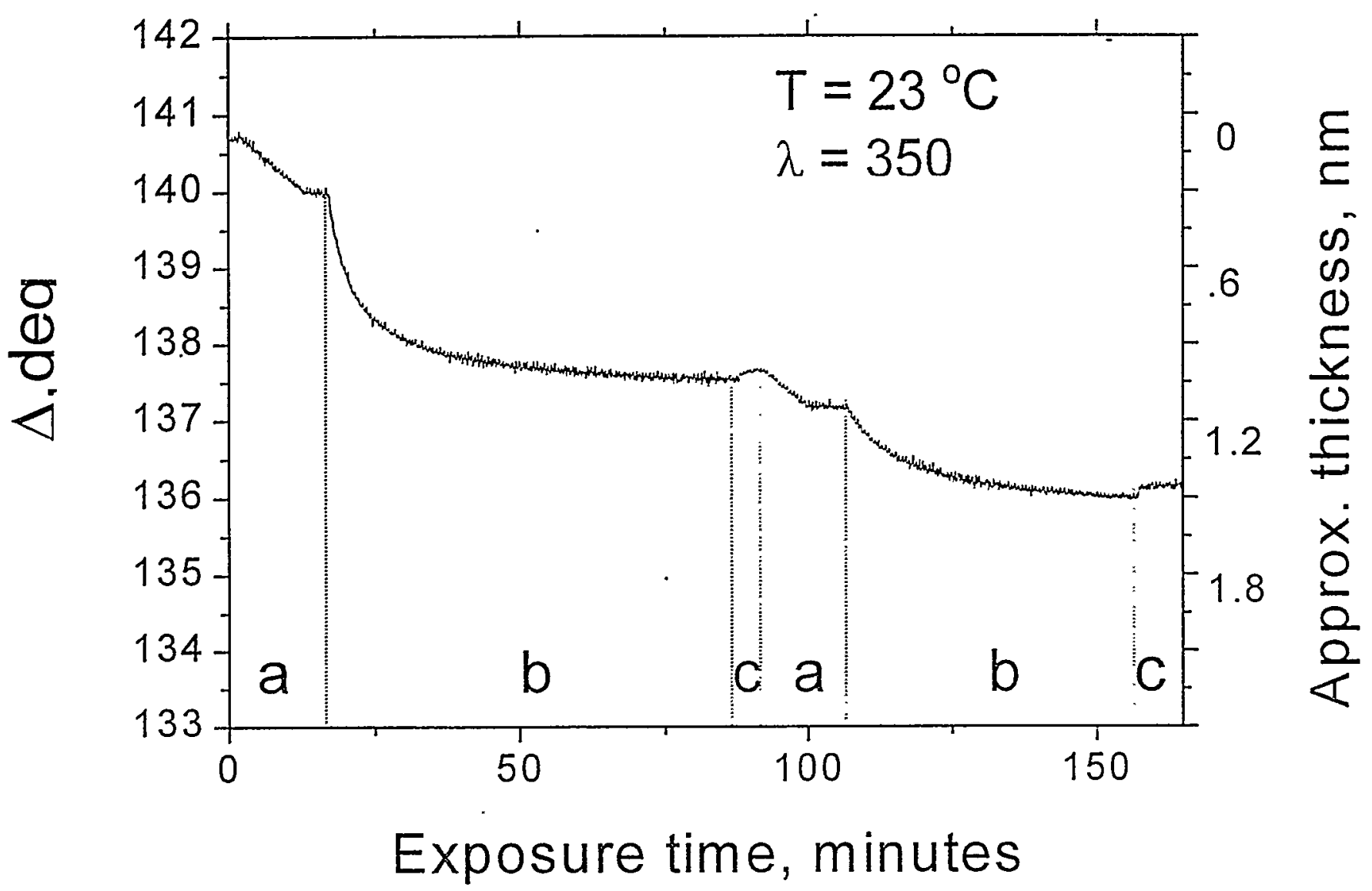

Figure 4. In-situ ellipsometric measurement of FOTS $+\mathrm{H}_{2} \mathrm{O}$ exposure at room temperature. Time increment (a): FOTS is admitted to a static pressure of 0.1 torr. Time increment (b): $\mathrm{H}_{2} \mathrm{O}$ added to a total pressure of 0.25 torr. Reaction of FOTS with $\mathrm{H}_{2} \mathrm{O}$ produces a stable film with self-limiting thickness of $\sim 1 \mathrm{~nm}$. The chamber is evacuated in time increment (c). Repeated cycles of FOTS and $\mathrm{H}_{2} \mathrm{O}$ exposure result in little additional film growth. Total film thickness saturates at $\sim 1$ monolayer. 


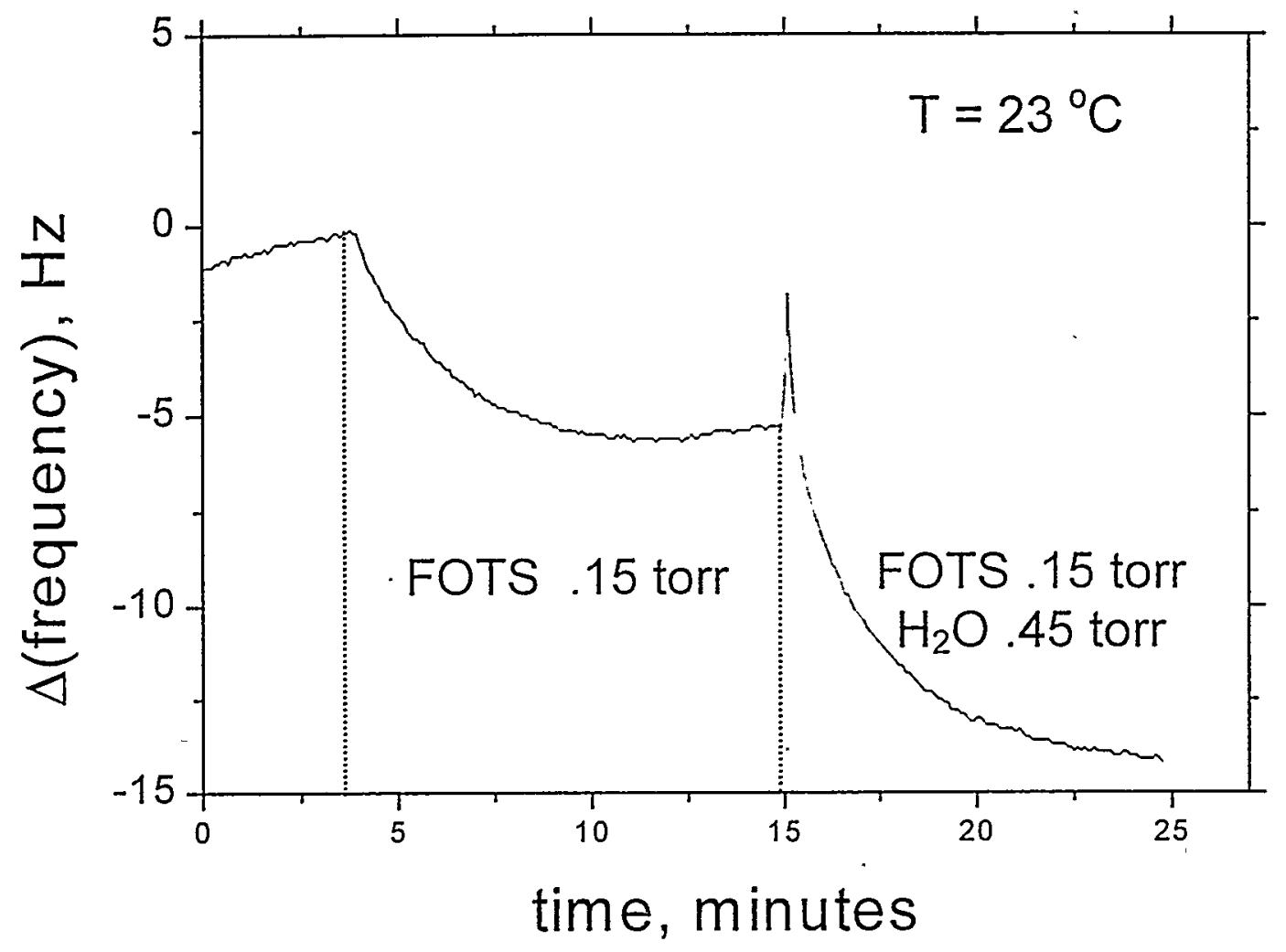

Figure 5. In-situ quartz crystal microbalance measurement of film growth, at conditions similar to those in Figure 4. Total frequency change of $14 \mathrm{~Hz}$ indicates a self limiting film density of $2.5 \times 10^{-9} \mathrm{~g} \mathrm{~cm}^{-2}$, or approx. 2.8 molecules $\mathrm{nm}^{-2}$. 


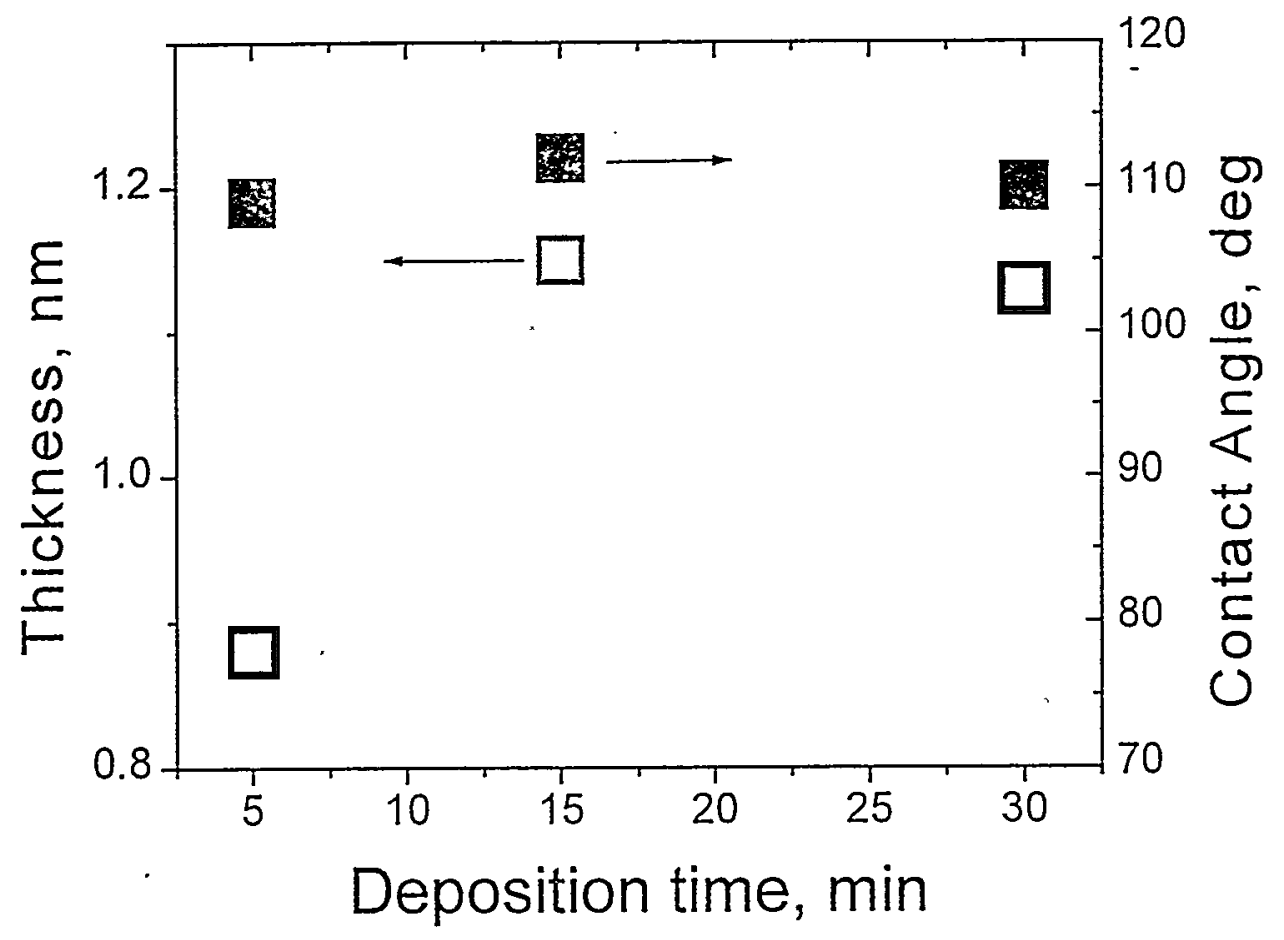

Figure 6. Thickness and contact angle of FOTS film as a function of FOTS $\div \mathrm{H}_{2} \mathrm{O}$ reaction time, at room temperature. FOTS pressure $=0.15$ torr, $\mathrm{H}_{2} \mathrm{O}$ pressure $=0.6$ torr. 


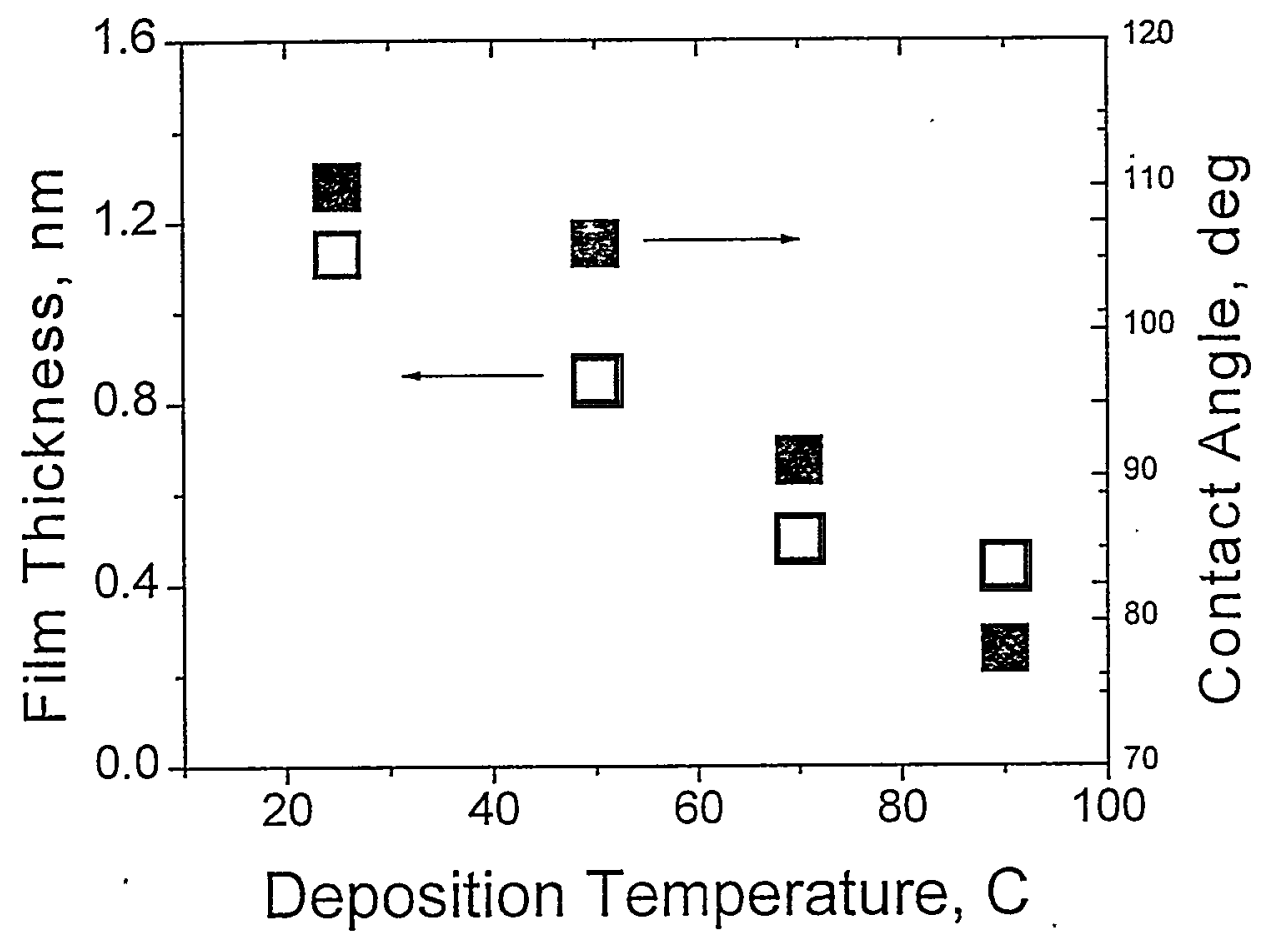

Figure 7. Thickness and contact angle of FOTS film as a function of substrate temperature for $\mathrm{FOTS}+\mathrm{H}_{2} \mathrm{O}$ reaction time $=30 \mathrm{~min}$. FOTS pressure $=0.15$ torr, $\mathrm{H}_{2} \mathrm{O}$ pressure $=0.6$ torr 


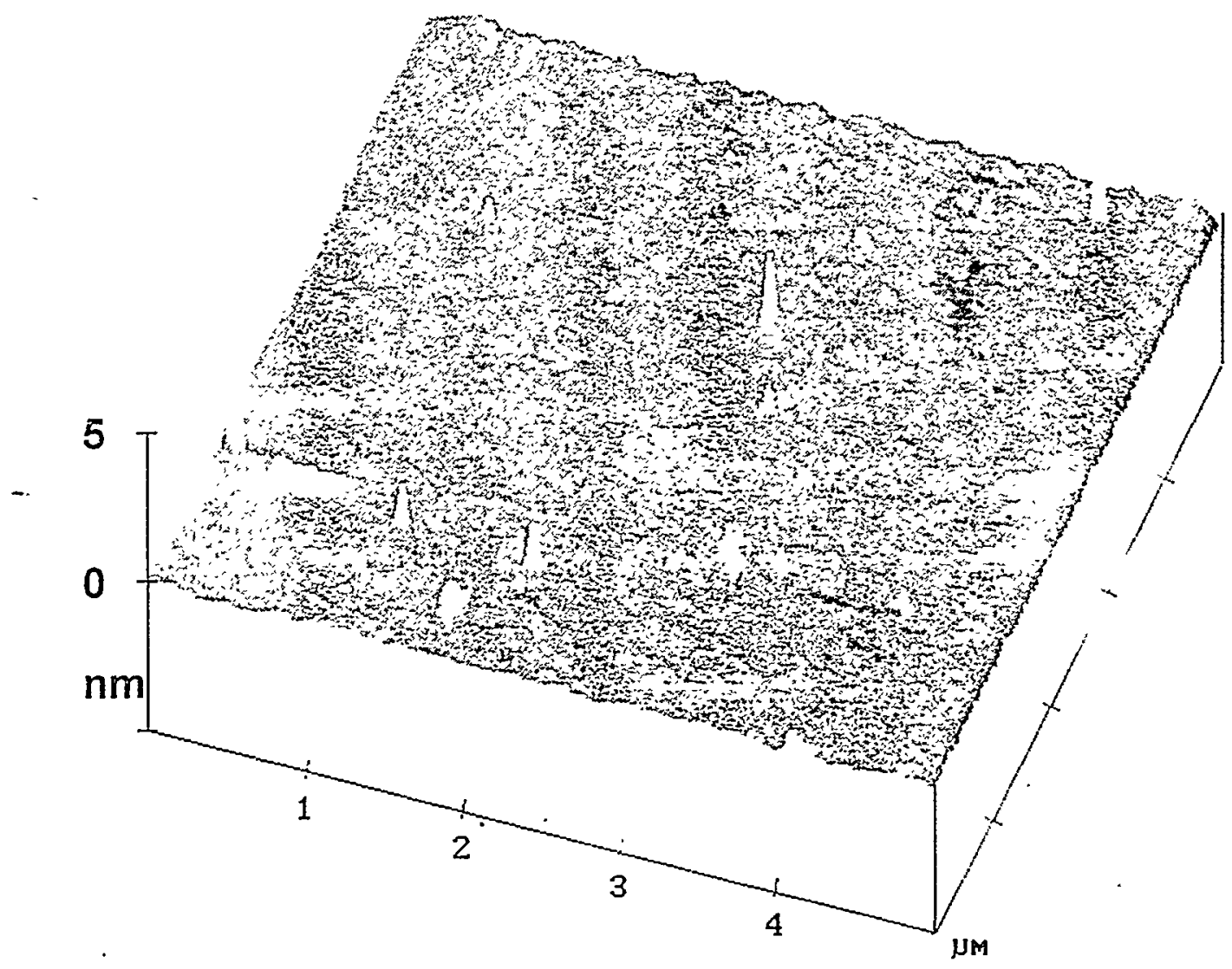

Figure 8. Atomic force microscope image of monolayer FOTS film on oxidized Si. Film appears continuous. with RMS roughness of $0.23 \mathrm{~nm}$ (same as original substrate). 


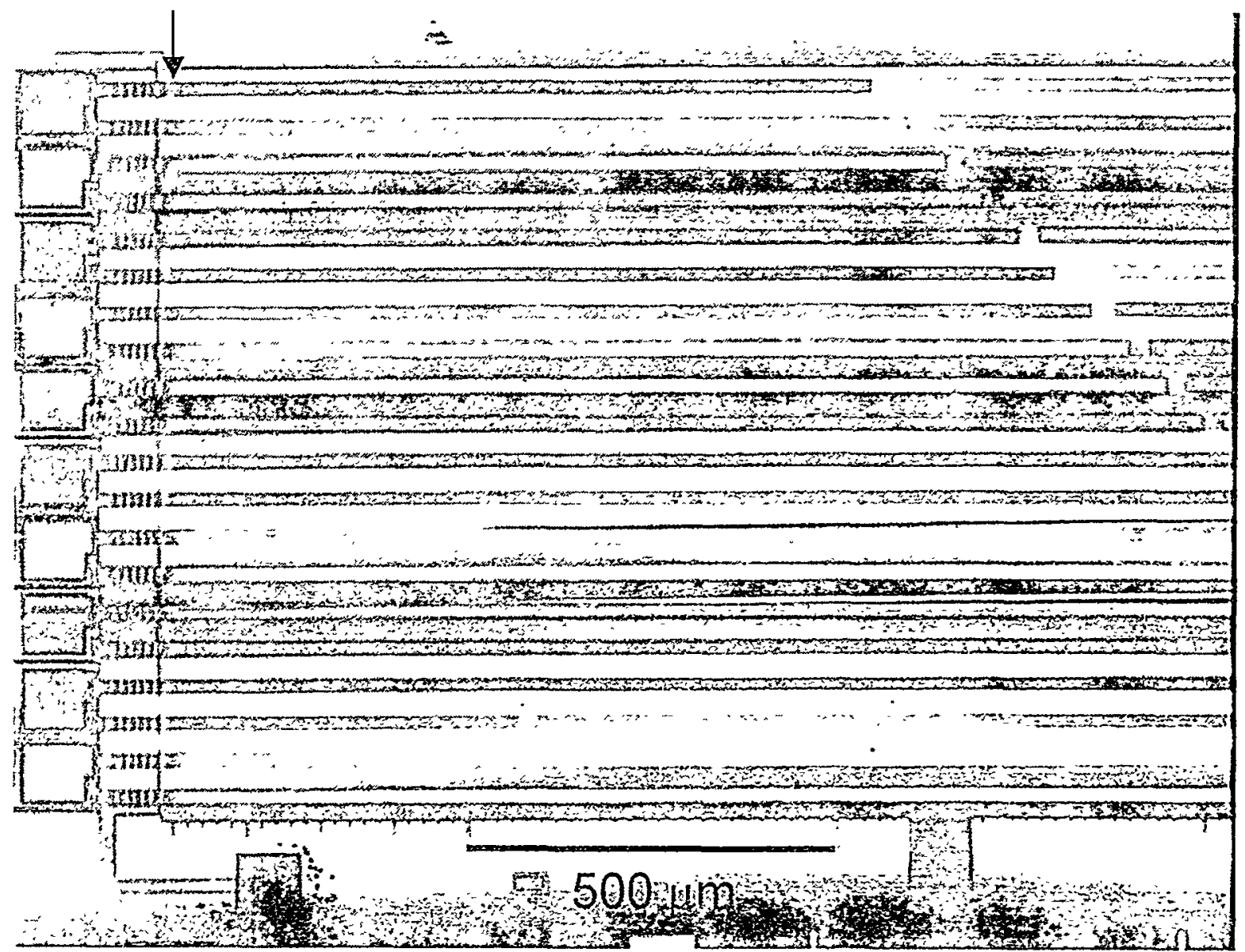

Figure 9. Cantilever beam adhesion test structure with clean, uncoated beams. after exposure to $95 \% \mathrm{RH} .>24 \mathrm{hr}$.. Support post and actuation pad are at the left-hand side of the structure. All beams are stuck to the landing pad near the actuation pad at the lefthand side of the picture, indicated by the arrow. 


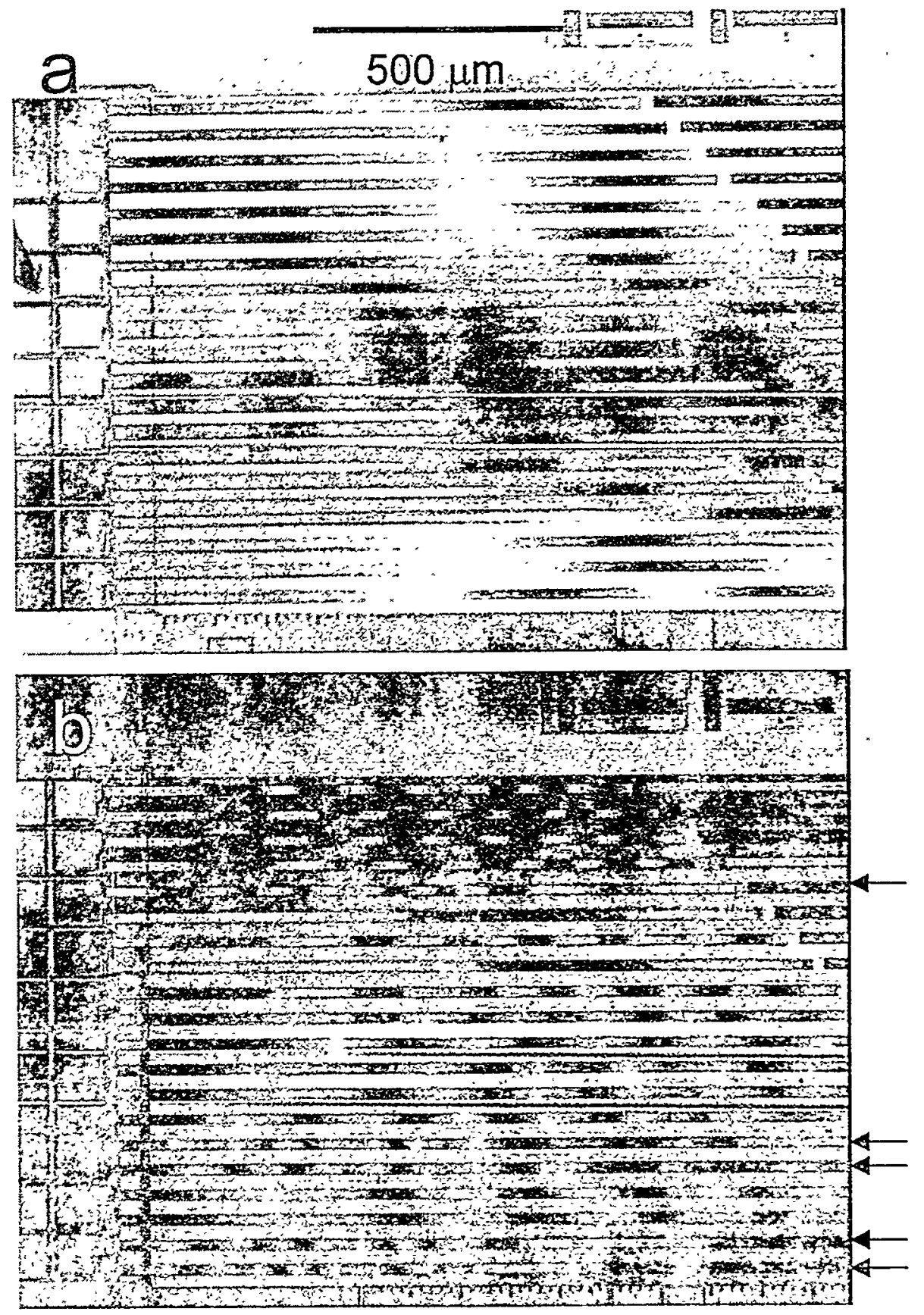

Figure 10. Cantilever beam adhesion test structure with clean. FOTS-coated beams. a)

After exposure at 5\% RH. All beams are free. b) After exposure to $95 \% \mathrm{RH}$ for $17 \mathrm{hr}$.

The beams indicated by arrows are adhered to the pad at a crack length of $700-1000 \mu \mathrm{m}$.

All others are either free or stuck only at their tips 


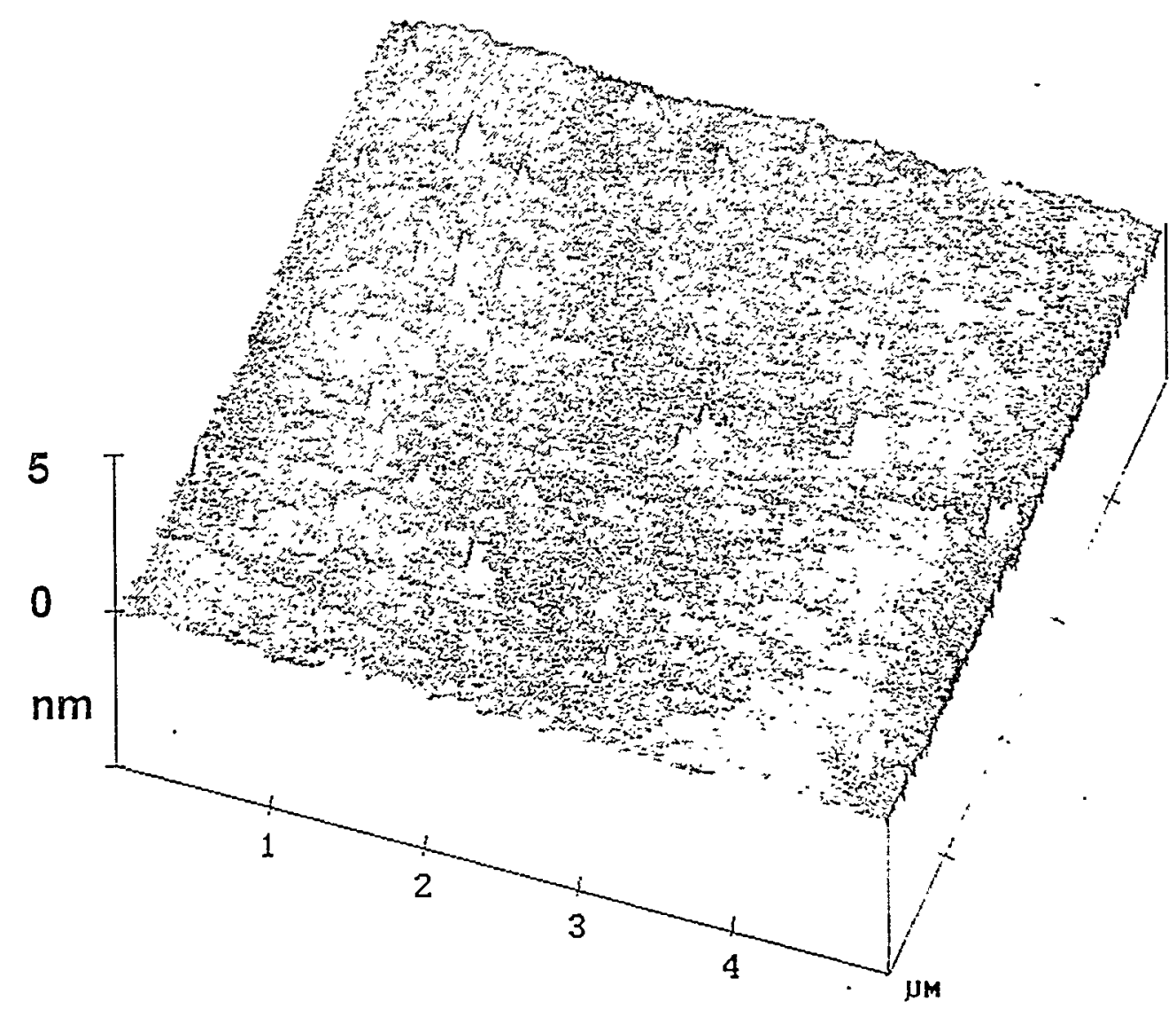

Figure 11. Atomic force microscope image of an FOTS-coated sample after exposure to $95 \% \mathrm{RH}$ at room temperature for $>24 \mathrm{hr}$. 
